\title{
Rapid loop-mediated isothermal amplification assays for grapevine yellows phytoplasmas on crude leaf-vein homogenate has the same performance as qPCR
}

\author{
Polona Kogovšek • Nataša Mehle • Anja Pugelj • Tjaša Jakomin • \\ Hans-Josef Schroers • Maja Ravnikar • Marina Dermastia
}

Accepted: 19 October 2016/Published online: 27 October 2016

(C) The Author(s) 2016. This article is published with open access at Springerlink.com

\begin{abstract}
A fluorescence-based real-time loop-mediated isothermal amplification (LAMP) assay for 'Candidatus Phytoplasama solani’ (Bois noir phytoplasma; BNp) detection was developed and optimised for rapid laboratory and on-site $\mathrm{BNp}$ detection. This assay is highly specific, rapid and as sensitive as qPCR. It was validated according to European and Mediterranean Plant Protection Organisation recommendations. In addition, 286 grapevine leaf samples from the 2015 growing season were tested with this new real-time LAMP assay and an assay previously developed for detection of Flavescence dorée phytoplasma (FDp). These LAMP assays for detection of both BNp and FDp used without any DNA extraction step, which is a required step for qPCR analysis, were comparably effective to qPCR, and positive results were obtained in less than $35 \mathrm{~min}$.
\end{abstract}

Electronic supplementary material The online version of this article (doi:10.1007/s10658-016-1070-z) contains supplementary material, which is available to authorized users.

P. Kogovšek $(\bowtie) \cdot$ N. Mehle · A. Pugelj • T. Jakomin • M. Ravnikar · M. Dermastia

Department of Biotechnology and Systems Biology, National Institute of Biology, Večna pot 111, 1000 Ljubljana, Slovenia e-mail: polona.kogovsek@nib.si

\section{H.-J. Schroers}

Agricultural Institute of Slovenia, Hacquetova ulica 17, 1000 Ljubljana, Slovenia

\section{Ravnikar}

University of Nova gorica, Vipavska cesta 13, 5000 Nova Gorica, Slovenia
Keywords Real-time LAMP. Grapevine yellows phytoplasma $\cdot$ Validation

\section{Introduction}

In grapevine (Vitis vinifera L.), phytoplasmas are associated with grapevine yellows (GYs) diseases, that occur in the majority of grapevine growing countries worldwide (Constable et al. 2003). 'Candidatus Phytoplasma solani' is from the stolbur group/ 16SrXII-A of phytoplasmas (Quaglino et al. 2013), and is associated with Bois noir disease (i.e., Bois noir phytoplasma; $\mathrm{BNp}$ ). In Europe, Bois noir disease is widespread. On the other hand, Flavescence dorée is associated with phytoplasmas belonging to the $16 \mathrm{SrV}$ group (i.e., Flavescence dorée phytoplasma; FDp) and this is the most severe of the GYs diseases. As such, FDp is listed in the EU2000/29 Council Directive on Harmful Organisms, and in the European and Mediterranean Plant Protection Organisation (EPPO) A2 quarantine list of pests. Typical symptoms of all GYs include leaf curling and discoloration of leaf veins and lamina, inter-vein yellowing or reddening (according to the variety), uneven or total lack of lignification of canes, flower abortion, and berry withering. Symptoms caused by $\mathrm{BNp}$ and FDp are not distinguishable by visual inspection and as the distribution of phytoplasma is uneven within a host that has a very low titre (Prezelj et al. 2013), only specific molecular approaches are suitable for the accurate and reliable detection of BNp and FDp. 
In diagnostic laboratories, assays based on real-time PCR (qPCR) are widely used for the detection of BNp and FDp (Angelini et al. 2007; Bianco et al. 2004; Galetto et al. 2005; Hren et al. 2007; Margaria et al. 2009; Pelletier et al. 2009). Furthermore, a protocol for the detection of FDp based on loop-mediated isothermal amplification (LAMP) assay was developed recently (Notomi et al. 2000; Kogovšek et al. 2015). LAMP is a highly specific and rapid technique, and it also circumvents the sensitivity of PCR and qPCR to inhibitors in plant extracts (Francois et al. 2011); furthermore, its isothermal nature provides the potential for it to be deployed in the field (Kogovšek et al. 2015; Tomlinson et al. 2010a). LAMP has shown a comparable or better performance to other detection methods and a wide applicability for the detection of plant pathogenic bacteria (Lenarčič et al. 2014), viroids (Lenarčič et al. 2013), fungi (Tomlinson et al. 2010b) and phytoplasmas (Bekele et al. 2011; Dickinson 2015; Hodgetts et al. 2011; Kogovšek et al. 2015; Tomlinson et al. 2010a).

In the present study, seven fluorescence-based realtime LAMP assays were designed for the specific detection of $\mathrm{BNp}$ and the best performing assay was verified. Additionally, a protocol was developed allowing rapid laboratory testing of phytoplasmas in grapevine crude leaf-vein homogenates. The performance of the LAMP assay was compared with the currently used qPCR protocols. This protocol includes the newly developed LAMP assay for BNp and the published LAMP assay for FDp (Kogovšek et al. 2015). These LAMP assays were shown here to be effective in the detection of both $\mathrm{BNp}$ and FDp in grapevine without any DNA extraction step, and with comparable sensitivity to that of qPCR. These LAMP protocols were also evaluated for on-site applications.

\section{Materials and methods}

Plant material, phytoplasma isolates

and other pathogens

The grapevine samples used for testing and validation of the LAMP assay were collected from Slovenian vineyards during the 2013 and 2014 growing seasons (Table 1). In addition, for the comparative study of LAMP and qPCR, 286 grapevine samples were collected in 2015 during an official survey for BNp and FDp. Excised leaf veins and berries, berry pedicels and tendrils were picked from symptomatic plants and stored at $-20{ }^{\circ} \mathrm{C}$ for further analysis. The status of the plants (i.e., BNp/FDp infected, non-infected) was confirmed by qPCR (Hren et al. 2007) following the procedure described by Mehle et al. (2013a, b). The healthy and BNp-infected grapevine samples included in the present study were of different cultivars (Supplementary Table S1 and S5). The phytoplasma strains from different $16 \mathrm{Sr}$ groups that were included in this study originated from the collections of the National Institute of Biology (NIB, Ljubljana, Slovenia), University of Bologna (Italy), University of Nottingham (UK), French National Institute for Agricultural Research (INRA, France), and University of Udine (Italy) (Table 1). In addition, the tests included: (i) plant pathogenic bacteria from the NIB collections (including uncharacterised grapevine bacterial isolates), the National Collection of Plant Pathogenic Bacteria (York, UK) and the collection of Instituto Valenciano de Investigaciones Agrarias (IVIA, Spain), and (ii) several taxa of fungi frequently occurring in vineyards from the collection of the Agricultural Institute of Slovenia (KIS, Ljubljana, Slovenia) (Table 1).

\section{LAMP primer design and reactions}

The sequences for the rRNA genes (i.e., 16S, 23S, ITS region) and secA, secY, stamp and tuf were retrieved from the NCBI and aligned using the VectorNTI software (InforMax). The regions of homology specific for the stolbur phytoplasma strain (16SrXII-A) were determined. The LAMP assays were designed for all seven regions, using the LAMP Designer software (Premier Biosoft), and primers were synthesised by Integrated DNA Technologies (Germany).

All LAMP reactions were performed in a $25-\mu \mathrm{L}$ reaction volume that contained $5 \mu \mathrm{L}$ sample DNA or homogenate, $2 \times$ Isothermal Master Mix (Optigene), $0.2 \mu \mathrm{M} \mathrm{F} 3$ and B3 primers, $2 \mu \mathrm{M}$ FIP and BIP primers, and $1 \mu \mathrm{M}$ F-loop and B-loop primers. The LAMP reactions were performed in 8-well strips, or 96-well plate in GenieII (Optigene) or Roche LC480 instruments, respectively. In the 'multi' LAMP (mLAMP) assays where secA (targeting $\mathrm{BNp}$; this study) and $23 \mathrm{~S}$ rRNA (targeting FDp) (Kogovšek et al. 2015) were combined, the same primer and reagent concentrations were used as above. For the LAMP product annealing temperature determination (i.e., $\mathrm{Tm}$ ), the fluorescence was detected during the cooling of the samples from $98{ }^{\circ} \mathrm{C}$ to $80{ }^{\circ} \mathrm{C}$ 


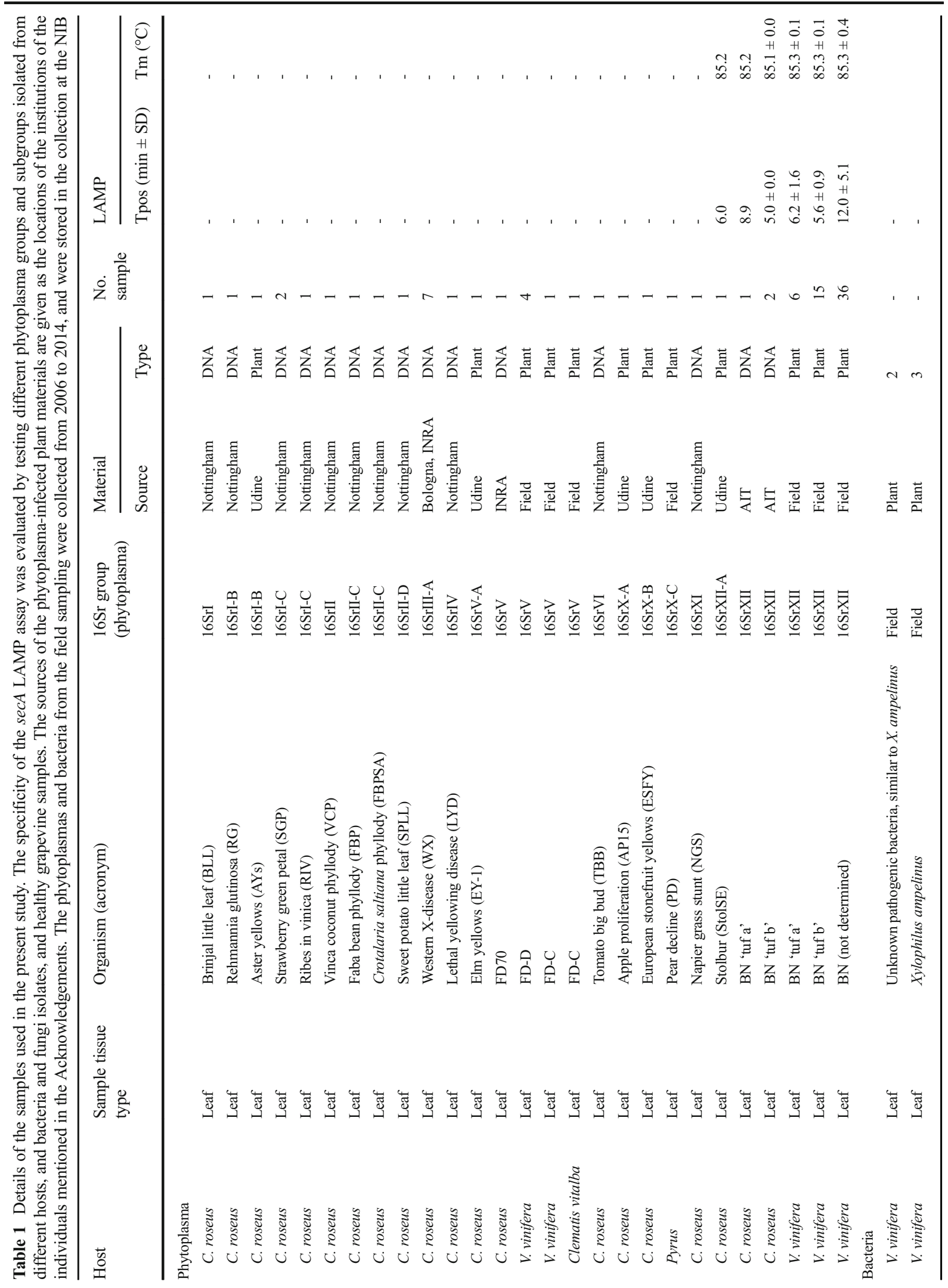




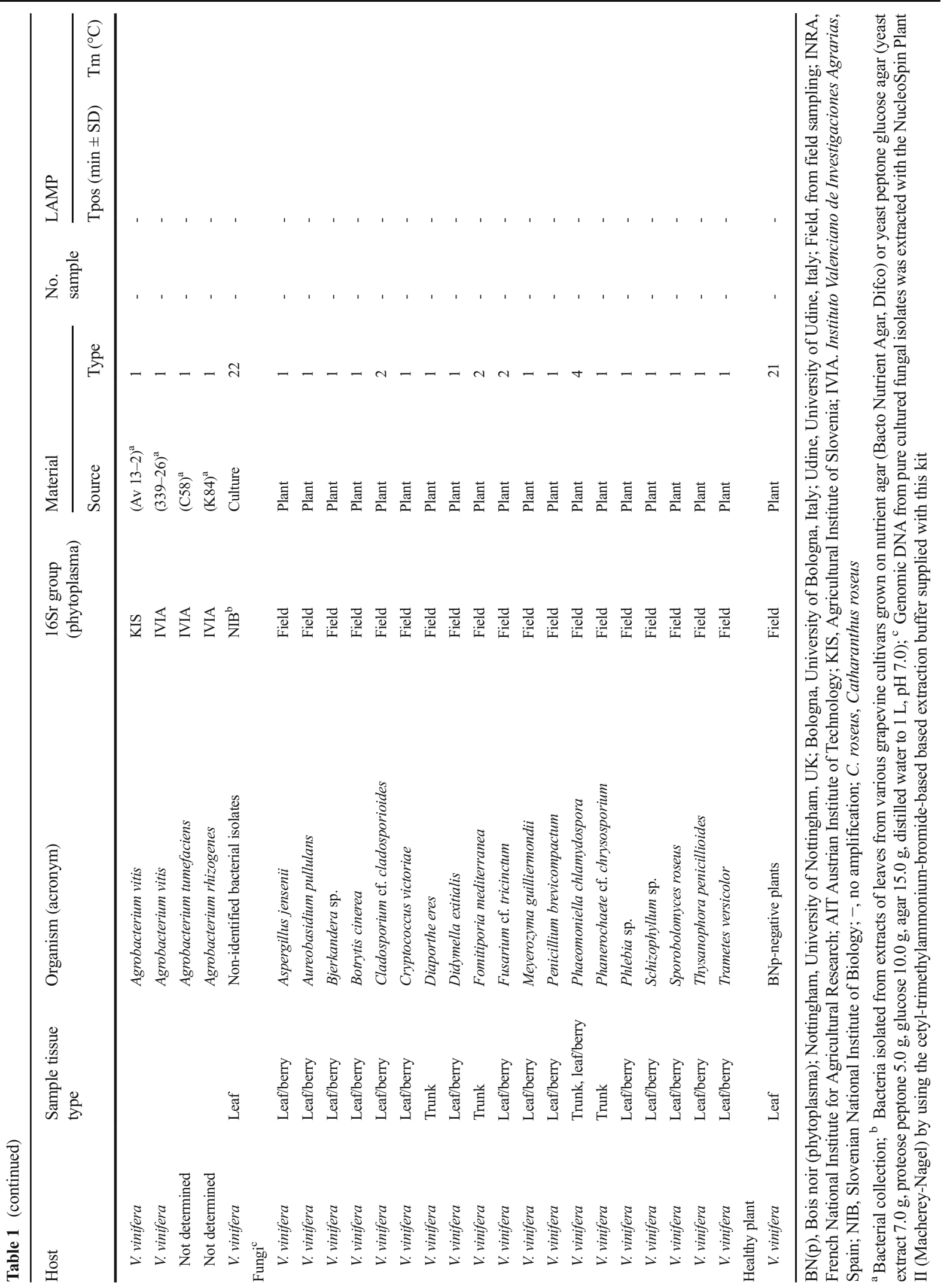


(GenieII) or during the heating of the samples from $62^{\circ} \mathrm{C}$ to $98{ }^{\circ} \mathrm{C}$ (Roche LC480). A sample was recognised as positive when the amplification curve was observed and the Tm was in the expected range in at least two replicates out of three. If only one out of three replicates was positive, the result was treated as inconclusive. All of the additional data regarding the Minimum Information for Publication of Quantitative Real-Time PCR Experiments guidelines (Bustin et al. 2010) for secA LAMP assay are given in Supplementary Table S2.

\section{LAMP assay selection and optimisation}

The performances of all of the seven LAMP assays were initially tested on a small set of BNp-positive, BNpnegative grapevine samples, and on phytoplasma isolates from other $16 \mathrm{Sr}$ groups, and bacteria. The LAMP assays were run at $62{ }^{\circ} \mathrm{C}$ and $65^{\circ} \mathrm{C}$. The LAMP assays that showed specific amplification and gave the shortest time of positivity (Tpos) at the selected temperature of amplification were taken forward for further testing (Supplementary Fig. S1).

\section{Validation of the LAMP $\sec A$ assay}

The $\sec A$ LAMP assay was validated according to the EPPO recommendations (EPPO 2014). The analytical sensitivity was evaluated by testing BNp-positive DNA that was diluted in DNA extracted from healthy grapevine midribs or in water. Three-fold dilutions were prepared and analysed with the LAMP and qPCR assays for the detection of BNp (Hren et al. 2007). This experiment was repeated four times, and each time the samples were analysed in triplicates, as a minimum, with each method. The analytical specificity was analysed by testing different BNp types (e.g., tuf a, tuf b), FDp, other phytoplasmas, bacteria, fungi and a healthy host (Table 1). Additionally, the sensitivities were compared to qPCR by testing a set of BNp-infected grapevine samples. The selectivity was evaluated by testing samples from various grapevine cultivars and tissues (Table 1). The repeatability was evaluated by analysing 3-5 replicates of DNA samples with various concentrations of BNp DNA. To assess reproducibility, the analyses were performed on up to 39 different days with freshly prepared reaction mix, and by up to three different operators and on two different devices (i.e., GenieII, Roche LC480), where one or more parameters, e.g., operator, device and/or day, were changed per repetition.
qPCR assays

All grapevine samples were tested for phytoplasmas (BNp, FDp) and the plant 18S rRNA gene (to confirm the DNA extraction success), with qPCR assays performed as previously described (Hren et al. 2007; Mehle et al. 2013b).

Leaf-vein crude homogenate testing using LAMP assays

The performance of secA LAMP assay was preliminarily evaluated on crude grapevine homogenates prepared with different homogenisation systems, i.e. different devices, lysing matrices, and buffers, thus assessing the applicability of different homogenisation approaches for direct testing (Supplementary Table S1). In a final comparative study we prepared samples with the FastPrep-24 (MP Biomedicals) protocol ( $40 \mathrm{~s}$ at $5 \mathrm{~m} / \mathrm{s}$ ), because of its comparably good performance with other protocols (Supplementary Table S1) and its routine use in a DNA extraction protocol (Mehle et al. 2013a). We additionally evaluated the analytical sensitivity of direct testing of leaf-vein homogenates prepared with Ultra Turrax Tube Drive device (UTTD, IKA). This device is favoured due to its cost and performance efficiencies and its on-site applicability for FDp detection (Kogovšek et al. 2015).

A comparative study was performed on 286 grapevine samples collected during an official survey in the 2015 growing season. One gram of grapevine plant material (i.e., leaf veins, tendrils, berries, berry pedicels) was added to $2 \mathrm{ml}$ ELISA buffer (Kogovšek et al. 2015) in $15 \mathrm{~mL}$ test-tubes with garnet matrix and ceramic spheres, and homogenised with FastPrep-24 (MP Biomedicals) for $40 \mathrm{~s}$ at $5 \mathrm{~m} / \mathrm{s}$. The homogenates then underwent DNA extraction following the procedure described by Mehle et al. (2013a). The aliquots of the original homogenates were directly tested without prior DNA extraction. The homogenates and the extracted DNA were 10-fold diluted in water before their addition to the LAMP and qPCR assays, respectively. The crude grapevine leaf-vein homogenates were tested with the validated LAMP assay, targeting BNp, and 23S rRNA LAMP assay targeting FDp (Kogovšek et al. 2015) and the results compared to qPCR testing of extracted DNA. Additionally, the LAMP COX assay (Tomlinson et al. 2010b) was used for confirmation of the capability of amplifying plant DNA in the sample. The analytical 
sensitivities of the on-site applicable leaf-vein crude homogenates testing were evaluated by testing five individual three-fold dilution series prepared from BNpinfected homogenates in healthy grapevine homogenate. The homogenates for the latter were prepared with an UTTD, and then directly tested with the LAMP assay. The results were compared to the standard $\mathrm{BNp}$ detection procedure in the laboratory that was based on qPCR analysis of the extracted DNA.

\section{Results and discussion}

In this study, seven LAMP assays were initially designed targeting diverse phytoplasma genes for the detection of $\mathrm{BNp}$ in grapevine samples. After the assay optimisation, their performances were compared. The best performing assay was validated according to the EPPO recommendations (EPPO 2014). In addition, the performance of the crude leaf-vein homogenate testing with the LAMP assay validated here for $\mathrm{BNp}$ and the earlier developed LAMP assay for FDp (Kogovšek et al. 2015) was compared to routine qPCR testing of the extracted DNA. The procedure of on-site testing of grapevine homogenates was developed and evaluated as well.

Primer design and evaluation of the LAMP assays

Sets of primers were designed according to the $16 \mathrm{~S}$ rRNA, 23S rRNA, ITS, secA, secY, stamp and tuf genes (Table 2, Supplementary Table S3), where regions of the sequence specific for $16 \mathrm{SrXII-A}$ phytoplasmas were identified. In terms of the Tpos, specificity and sensitivity, the performance of each LAMP assay was evaluated by analysing a set of samples with different titres of

Table 2 secA LAMP primer sets designed for detection of BNp

\begin{tabular}{ll}
\hline Primer & Primer sequence $\left(5^{\prime}-3^{\prime}\right)$ \\
\hline $\sec A-\mathrm{F} 3$ & TTCCACCAAATCTTTGAGCT \\
$\sec A$-B3 & ACAATAGCTACCAATATGGCAG \\
$\sec A$-FIP & AATTAAGAGGACGTGCCGGTCGTTC \\
& GTCTTCGCTGGAAA \\
$\sec A$-BIP & TCCTAAAACCGCCAAACCTCCGAAG \\
& AGGAACTGATATTCGCTT \\
$\sec A$-LoopF & GAGATCCTGGTTATTCTCGCTT \\
& TTCAACAACGCCTTCACCT \\
\hline
\end{tabular}

$\mathrm{BNp}$, along with negative plant samples. Almost all of assays performed better at $62{ }^{\circ} \mathrm{C}$ then at $65^{\circ} \mathrm{C}$ (data not shown). The $\sec Y$ assay did not show any amplification under the conditions tested, and the 16S rRNA and ITS assays showed non-specific amplification with unrelated phytoplasmas (data not shown); these were thus excluded from further analysis. The remaining LAMP assays, i.e. $23 \mathrm{~S}$ rRNA, secA, stamp and tuf, were further evaluated and the secA, stamp and tuf assays showed higher specificities than the 23S rRNA assays (see Table 1 for the secA LAMP assay, data not shown for the other assays). Although the stamp assay was sufficiently specific, its Tpos was longer than that of the secA and tuf assays (data not shown), and it was thus excluded from further testing. The secA LAMP assay showed higher sensitivity than the tuf LAMP assay (data not shown), and was therefore selected for further validation here.

To optimise the procedure for GYs phytoplasma detection, an mLAMP assay for simultaneous detection of BNp and FDp was applied and evaluated, where the $\sec A$ assay developed in this study and the earlier created 23S rRNA (Kogovšek et al. 2015) LAMP assays were combined. The mLAMP assay gave reliable results in terms of the amplification and Tm analysis (data not shown). However, the Tm analysis of the amplified product does not allow for differentiation between the two GYs phytoplasmas, as both have a similar Tm; therefore, the mLAMP assay was not evaluated further.

\section{Sensitivity of the secA LAMP assay}

The sensitivity of the secA LAMP assay and the qPCR assay for the detection of $\mathrm{BNp}$ (Hren et al. 2007) was compared. The testing of the dilution series showed that the $\sec A$ LAMP assay detected as low as 9-27 BNp copies in a reaction, with all five replicates identified as positive (Table 3). Lower amounts of the BNp DNA in the reaction resulted in lower numbers of positive replicates. Nevertheless, results of the secA LAMP assay suggested that it had a similar sensitivity compared to the qPCR assay for BNp detection (Supplementary Table S4).

The secA LAMP assay was further evaluated by testing grapevine leaf-vein samples with different amounts of BNp DNA, as estimated using qPCR. The diagnostic sensitivity of the $\sec A$ LAMP assay was $100 \%$, which was supported by the detection of BNp in all of the 57 samples tested (Table 1, Supplementary 
Table 3 Analytical sensitivities of the secA LAMP assays tested on extracted DNA in parallel with the qPCR. Three-fold dilution series of $\mathrm{BNp}$-infected DNA were prepared in healthy grapevine DNA, and tested in at least triplicate. The mean Cq, Tpos and Tm ( \pm standard deviation) are shown

\begin{tabular}{|c|c|c|c|c|}
\hline \multirow{2}{*}{$\begin{array}{l}\text { Fold } \\
\text { dilution }\end{array}$} & \multirow{2}{*}{$\begin{array}{l}\text { Estimated } \\
\text { copy number }\end{array}$} & \multirow{2}{*}{$\begin{array}{l}\text { qPCR } \\
(\mathrm{Cq} \pm \mathrm{SD})\end{array}$} & \multicolumn{2}{|l|}{ LAMP } \\
\hline & & & $\begin{array}{l}\text { Tpos } \\
(\min \pm \mathrm{SD})\end{array}$ & $\begin{array}{l}\mathrm{Tm} \\
\left({ }^{\circ} \mathrm{C} \pm \mathrm{SD}\right)\end{array}$ \\
\hline 10 & $729-2187$ & $31.8 \pm 0.1$ & $6.1 \pm 0.2$ & $85.6 \pm 0.1$ \\
\hline 30 & $243-729$ & $33.2 \pm 0.2$ & $8.1 \pm 0.8$ & $85.4 \pm 0.1$ \\
\hline 90 & $81-243$ & $35.4 \pm 1.1$ & $9.8 \pm 1.2$ & $85.3 \pm 0.1$ \\
\hline 270 & $27-81$ & $36.4 \pm 0.3$ & $11.9 \pm 2.5$ & $85.3 \pm 0.0$ \\
\hline 810 & $9-27$ & $37.3 \pm 0.4^{\mathrm{a}}$ & $13.3 \pm 2.4$ & $85.5 \pm 0.1$ \\
\hline 2430 & $3-9$ & $37.6 \pm 0.4^{\mathrm{b}}$ & $21.3 \pm 12.4^{\mathrm{c}}$ & $85.2 \pm 0.1$ \\
\hline 7290 & $1-3$ & $38.0^{\mathrm{d}}$ & $17.1^{\mathrm{d}}$ & 85.6 \\
\hline 21,870 & 0 & neg & neg & l \\
\hline 65,610 & 0 & neg & neg & l \\
\hline
\end{tabular}

${ }^{\mathrm{a}}$ Four out of five replicates were positive; ${ }^{\mathrm{b}}$ three out of five replicates were positive; ${ }^{c}$ two out of five replicates were positive; $\mathrm{d}$ one out of five replicates was positive; neg, no amplification was detected; /, no Tm value available

Table S5). However, in five DNA samples with low BNp titres $(\mathrm{Cq}>34.5)$, BNp DNA was only confirmed after the undiluted sample DNA was re-analysed. These data showed again that the LAMP reaction is less sensitive to inhibition, and allow analysis of undiluted grapevine DNA samples (Kogovšek et al. 2015). Therefore, testing of undiluted DNA is recommended to avoid false-negative results. All of the positive results from LAMP reactions were observed in less than $35 \mathrm{~min}$ of amplification, with a mean Tpos of $9.3 \pm 4.6 \mathrm{~min}$. Rapidity of these reactions suggests the possibility of its use for rapid diagnostics.

\section{Specificity and selectivity}

The analytical specificity of the secA LAMP assay was first evaluated by in-silico analysis and showed high predicted specificity for the 16SrXII-A phytoplasmas, including $\mathrm{BNp}$ (data not shown).

The specificity of the $\sec A$ LAMP assay was confirmed through the analysis of the samples listed in Table 1 and in Supplementary Table S5. All of the data obtained with the secA LAMP assay were in agreement with the qPCR data obtained according to Hren et al. (2007). The developed assay was not designed to discriminate tuf type-a and tuf type-b BNpd (Foissac et al.
2013), therefore no difference in amplification of these tuf-types was detected. No cross-reactivity of the secA LAMP assay was observed among the phytoplasma DNA from other 16Sr groups, including FDp from grapevine samples from several European winegrowing areas, and the pathogenic and non-pathogenic bacteria and fungi and the healthy host (Table 1).

The Tm for the specific amplicon ranged from $84^{\circ} \mathrm{C}$ to $85^{\circ} \mathrm{C}$ on the GenieII apparatus (data not shown), and from $85{ }^{\circ} \mathrm{C}$ to $86{ }^{\circ} \mathrm{C}$ on the Roche LC480 system (Table 1). This variation between the different instruments is expected and Tm should be experimentally determined for the individual instruments (Kogovšek et al. 2015). In the same five 10-folddiluted DNA samples with low BNp titres $(\mathrm{Cq}>34.5)$ discussed above with respect to the sensitivity, up to $2{ }^{\circ} \mathrm{C}$ higher $\mathrm{Tm}$ were determined, while the undiluted DNA from the samples gave a Tm in the expected range (Supplementary Table S5).

Repeatability and reproducibility

Repeatability and reproducibility of the assays were evaluated by analysis of several replicates of DNA samples with various BNp DNA titres. When testing replicates of the same sample with high and medium titres of BNp DNA (i.e., qPCR $\mathrm{Cq}<33$ ), the assay repeatability was $100 \%$, meaning that all of the replicates gave a positive result (Supplementary Table S4). At lower BNp concentrations, the detection of the $\mathrm{BNp}$ DNA using the $\sec A$ LAMP assay varied, giving positive and negative results, and this can be attributed to stochastic effects in the target copy distribution in the replicates (Hren et al. 2007). These data were $100 \%$ reproducible when tested with the different devices, and by different operators, on different days, and with different reaction mixes (Supplementary Table S6).

Comparative study of the analysis of leaf-vein crude homogenates with the LAMP assay and qPCR testing of DNA

To determine the performance of the validated LAMP assays for the BNp detection (this study) and FDp detection (Kogovšek et al. 2015), an extensive comparative study was set up in 2015 . We analysed all grapevine samples received for GYs disease testing during the official national survey. A total of 286 samples were processed. Crude leaf-vein homogenates were tested 
with the LAMP assays, and were further subjected to DNA extraction for qPCR testing (Hren et al. 2007).

BNp was confirmed by qPCR BNp in 208 out of 286 samples and FDp in 24 samples, with four samples being positive for both BNp and FDp (Supplementary Table S8). With the LAMP assays, the sanitary status of 284 out of the 286 samples tested (i.e. $99.3 \%$ ) were correctly determined, and only two samples (D211/15, D333/15) were misinterpreted (Table 4). In sample $\mathrm{D} 333 / 15$, the concentration of $\mathrm{BNp}$ was low (mean Cq, 32.4), and it was even lower in sample D211/15, where BNp was detected with qPCR only in an undiluted DNA sample; testing of the 10-fold dilution of this DNA resulted in only one positive replicate $(\mathrm{Cq}, 38.9)$ out of three tested. In five BNp-infected samples with $\mathrm{Cq}>32$, and in one FDp-infected sample with Cq 31.4, the results obtained by the LAMP assays were inconclusive. Only one positive replicate out of three tested indicated low phytoplasma levels in the sample. In the case of the rapid in-laboratory screening of the crude homogenates with LAMP assays, DNA would be extracted from these samples and the DNA tested by qPCR.

The performance of both of the LAMP assays on crude homogenates was also determined in terms of Tpos and Tm (Supplementary Table S8). All of the LAMP reactions gave positive results in up to $35 \mathrm{~min}$ of amplification, with means of $17.3 \mathrm{~min}$ and $12.7 \mathrm{~min}$ for FDp and BNp, respectively. The Tm values of the
Table 5 Analytical sensitivity of the secA LAMP assay applied in the direct homogenate testing in parallel with the qPCR for the extracted DNA. A three-fold dilution series of $\mathrm{BNp}$-infected plant material was prepared in healthy grapevine material and tested in triplicate, except for the 270 -fold diluted sample, which was tested in duplicate with the LAMP assay. The mean Cq, Tpos and Tm ( \pm standard deviation) are shown

\begin{tabular}{|c|c|c|c|c|}
\hline \multirow{2}{*}{$\begin{array}{l}\text { Fold } \\
\text { dilution }\end{array}$} & \multirow{2}{*}{$\begin{array}{l}\text { Estimated } \\
\text { copy number }\end{array}$} & \multirow{2}{*}{$\begin{array}{l}\mathrm{qPCR} \\
(\mathrm{Cq} \pm \mathrm{SD})\end{array}$} & \multicolumn{2}{|l|}{ LAMP } \\
\hline & & & $\begin{array}{l}\text { Tpos } \\
(\min ; \pm \mathrm{SD})\end{array}$ & $\begin{array}{l}\mathrm{Tm} \\
\left({ }^{\circ} \mathrm{C} ; \pm \mathrm{SD}\right)\end{array}$ \\
\hline 10 & $81-243$ & $32.4 \pm 0.1$ & $20.4 \pm 3.5$ & $85.5 \pm 0.1$ \\
\hline 30 & $27-81$ & $34.0 \pm 0.2$ & $14.7 \pm 3.2$ & $85.4 \pm 0.1$ \\
\hline 90 & $9-27$ & $35.0 \pm 0.5$ & $24.8 \pm 14.1$ & $85.2 \pm 0.1$ \\
\hline 270 & $3-9$ & $36.0 \pm 0.4$ & $15.4^{\mathrm{a}}$ & $85.2^{\mathrm{a}}$ \\
\hline 810 & $1-3$ & $36.2 \pm 0.8$ & neg & I \\
\hline 2430 & 0 & neg & neg & / \\
\hline 7290 & 0 & neg & neg & l \\
\hline 21,870 & 0 & neg & neg & / \\
\hline
\end{tabular}

${ }^{\text {a One replicate out of two tested was positive; neg, no amplifica- }}$ tion was detected; /, no Tm value available

amplified products were in the expected range (23S rRNA assay Tm, from $84{ }^{\circ} \mathrm{C}$ to $86{ }^{\circ} \mathrm{C}$ ). The variation in the Tm observed for the secA LAMP assay $\left(84^{\circ} \mathrm{C}\right.$ to $87^{\circ} \mathrm{C}$ ) was due to the non-optimal reaction conditions in one of the LAMP runs (samples D267/15-D275/15), confirmed by the irregularities in the shapes of the amplification curves (data not shown). However, not

Table 4 Overview of the LAMP and qPCR comparative study results

\begin{tabular}{|c|c|c|c|c|}
\hline qPCR results $(\mathrm{Cq})$ & No. of samples & $\mathrm{LAMP}=\mathrm{qPCR}$ & $\mathrm{LAMP} \approx \mathrm{qPCR}^{\mathrm{a}}$ & $\mathrm{LAMP} \neq \mathrm{qPCR}$ \\
\hline BNp neg, FDp neg & 50 & 50 & 0 & 0 \\
\hline BNp neg, FDp pos $(\mathrm{Cq}<31)$ & 22 & 22 & 0 & 0 \\
\hline BNp neg, FDp pos $(\mathrm{Cq}>31)$ & 2 & 2 & 0 & 0 \\
\hline BNp pos $(\mathrm{Cq}>31)$, FDp pos $(\mathrm{Cq}<31)$ & 1 & 0 & $1^{\mathrm{b}}$ & 0 \\
\hline BNp pos $(\mathrm{Cq}<31)$, FDp pos $(\mathrm{Cq}<31)$ & 1 & 1 & 0 & 0 \\
\hline $\mathrm{BNp}$ pos $(\mathrm{Cq}<31)$, FDp pos $(\mathrm{Cq}>31)$ & 2 & 1 & $1^{\mathrm{c}}$ & 0 \\
\hline BNp pos $(\mathrm{Cq}<31)$, FDp neg & 187 & 187 & 0 & 0 \\
\hline BNp pos $(\mathrm{Cq}>31)$, FDp neg & 21 & 15 & 4 & 2 \\
\hline Total & 286 & 278 & 6 & 2 \\
\hline
\end{tabular}

$\overline{L A M P}$ qPCR Number of samples equally diagnosed, LAMP qPCR Number of samples with inconclusive results with LAMP, LAMP $\neq$ $q P C R$ Number of samples differentially diagnosed. Neg Negative, pos Positive

${ }^{\text {a }}$ One parallel out of three tested (1/3) was positive with LAMP

${ }^{\mathrm{b}}$ LAMP BN (1/3), LAMP FD positive

${ }^{\mathrm{c}}$ LAMP BN pos, LAMP FD (1/3) 
including the Tm values of these samples, the Tm of the secA LAMP assays were from $84{ }^{\circ} \mathrm{C}$ to $85^{\circ} \mathrm{C}$. In both the $\sec A$ and $23 \mathrm{~S}$ rRNA LAMP assays, the Tm of the reactions on the crude grapevine leaf-vein homogenates was slightly lower than that in the reactions with the extracted DNA (Kogovšek et al. 2015). The variation in the Tm of the amplified product is most probably due to matrix interference (i.e., high plant-cell components) influencing the melting of the amplified product, which was previously observed at the DNA level. An influence of the sample matrix on Tm was also observed in the testing of the homogenates prepared with Na-acetate buffer, where the Tm varied by up to $2{ }^{\circ} \mathrm{C}$ in individual replicates of the same sample (data not shown). However, the exact mechanism(s) of the matrix influence on the melting curve analysis and consequent $\mathrm{Tm}$ values is not yet known.

In addition, homogenisation with the on-site applicable UTTD was further evaluated in terms of the analytical sensitivity. The homogenisation procedure with the UTTD was shown to allow the detection of as low as three to nine copies of BNp DNA in a homogenate sample (Table 5). Lower amounts of BNp DNA in the reaction reduced the number of positive replicates. Nevertheless, based on all of the data from the on-site BNp testing approach, it was similar to the qPCR assay, where extracted DNA was tested (Supplementary Table S7).

\section{Conclusions}

The secA LAMP assay was developed and validated for the detection of BNp in extracted grapevine DNA. The results showed that the assay is fast, highly specific, and similarly sensitive as qPCR. A new assay was validated in accordance with EPPO recommendations. The assay can be used together with the LAMP assay for FDp detection (Kogovšek et al. 2015) and is innovative inlaboratory and on-site rapid testing of grapevine crude homogenates of different tissues. LAMP assays for $\mathrm{BNp}$ and FDp gave positive reaction results in 6-35 $\mathrm{min}$ which is therefore sufficient amplification time frame for GY phytoplasma detection. Performance of LAMP assays of selected grapevine yellows phytoplasmas on crude leaf vein homogenates provided similar results as the more laborious qPCR assay on extracted DNA from the same samples.
Acknowledgments The authors thank Ana Kompan, Larisa Gregur and Špela Prijatelj Novak for excellent technical support. Samples were taken during the official survey for BNp and FDp in Slovenia by the Slovenian Phytosanitary Administration. The authors would also like to thank Phil Jones (Rothamsted Research, UK), Assunta Bertaccini (University of Bologna, Italy), Elisabeth Boudon-Padieu and Xavier Foissac (INRA, France), Ruggero Osler and Paolo Ermacora (University of Udine, Italy), Matthew Dickinson (University of Nottingham, UK), Günter Brader (AIT Austrian Institute of Technology GmbH, Austria), Instituto Valenciano de Investigaciones Agrarias (IVIA, Spain), Slovenian Phytosanitary Administration Inspectors, and Tanja Dreo and Manca Pirc (NIB, Slovenia) for providing bacterial isolates/ samples. Fungal taxa included in this study were isolated in the context of FP7 ERA-Net Project Core Organic II, Vineman.org. Language revision was carried out by Christopher Berrie.

\section{Compliance with ethical standards}

Conflict of interest The authors declare that they have no conflict of interest.

Funding This study was financially supported by the Slovenian Research Agency (project no. L4-5525) and by Euphresco Grafdepi 2.

Open Access This article is distributed under the terms of the Creative Commons Attribution 4.0 International License (http:// creativecommons.org/licenses/by/4.0/), which permits unrestricted use, distribution, and reproduction in any medium, provided you give appropriate credit to the original author(s) and the source, provide a link to the Creative Commons license, and indicate if changes were made.

\section{References}

Angelini, E., Luca Bianchi, G., Filippin, L., Morassutti, C., \& Borgo, M. (2007). A new TaqMan method for the identification of phytoplasmas associated with grapevine yellows by real-time PCR assay. Journal of Microbiological Methods, 68(3), 613-622.

Bekele, B., Hodgetts, J., Tomlinson, J., Boonham, N., Nikolić, P., Swarbrick, P., et al. (2011). Use of a real-time LAMP isothermal assay for detecting 16SrII and XII phytoplasmas in fruit and weeds of the Ethiopian Rift Valley. Plant Pathology, 60(2), 345-355.

Bianco, P. A., Casati, P., \& Marziliano, N. (2004). Detection of phytoplasmas associated with grapevine flavescence doree disease using real-time PCR. Journal of Plant Pathology, 86, 257-261.

Bustin, S. A., Beaulieu, J.-F., Huggett, J., Jaggi, R., Kibenge, F. S. B., Olsvik, P. A., et al. (2010). MIQE précis: practical implementation of minimum standard guidelines for fluorescence-based quantitative real-time PCR experiments. BMC Molecular Biology, 11. doi:10.1186/14712199-11-74. 
Constable, F. E., Gibb, K. S., \& Symons, R. H. (2003). Seasonal distribution of phytoplasmas in Australian grapevines. Plant Pathology, 52, 267-276.

Dickinson, M. (2015). Loop-mediated isothermal amplification (LAMP) for detection of phytoplasmas in the field. In C. Lacomme (Ed.), Methods in molecular biology: plant pathology (Vol. 1302, pp. 99-111). New York: Springer.

EPPO (2014). Specific requirements for laboratories preparing accreditation for a plant pest diagnostic activity PM7/98 (2). EPPO Bulletin, 44, 117-147.

Foissac, X., Carle, P., Fabre, A., Salar, P., Danet, J.-L., \& StolburEuromed consortium, NN (2013). "Candidatus phytoplasma solani" genome project and genetic diversity in the EuroMediterranean basin. 3rd European Bois noir Workshop (pp. 11-13). Barcelona: Proceedings of the 3rd European Bois noir Workshop.

Francois, P., Tangomo, M., Hibbs, J., Bonetti, E. J., Boehme, C. C., Notomi, T., et al. (2011). Robustness of a loop-mediated isothermal amplification reaction for diagnostic applications. FEMS Immunology and Medical Microbiology, 62, 41-48.

Galetto, L., Bosco, D., \& Marzachi, C. (2005). Universal and group-specific real-time PCR diagnosis of flavescence doree $(16 \mathrm{Sr}-\mathrm{V})$, bois noir $(16 \mathrm{Sr}-\mathrm{XII})$ and apple proliferation $(16 \mathrm{Sr}-$ $\mathrm{X})$ phytoplasmas from field-collected plant hosts and insect vectors. Annals of Applied Biology, 147(2), 191-201.

Hodgetts, J., Tomlinson, J., Boonham, N., Gonzalez-Martin, I., Nikolić, P., Swarbrick, P., et al. (2011). Development of rapid in-field loop-mediated isothermal amplification (LAMP) assays for phytoplasmas. Bulletin of Insectology, 64, 41-42.

Hren, M., Boben, J., Rotter, A., Kralj, P., Gruden, K., \& Ravnikar, M. (2007). Real-time PCR detection systems for flavescence dorée and bois noir phytoplasmas in grapevine: comparison with conventional PCR detection and application in diagnostics. Plant Pathology, 56, 785-796.

Kogovšek, P., Hodgetts, J., Hall, J., Prezelj, N., Nikolić, P., Mehle, N., et al. (2015). LAMP assay and rapid sample preparation method for on-site detection of flavescence doree phytoplasma in grapevine. Plant Pathology, 64(2), 286-296.

Lenarčič, R., Morisset, D., Mehle, N., \& Ravnikar, M. (2013). Fast real-time detection of potato spindle tuber viroid by RTLAMP. Plant Pathology, 62(5), 1147-1156.

Lenarčič, R., Morisset, D., Pirc, M., Llop, P., Ravnikar, M., \& Dreo, T. (2014). Loop-mediated isothermal amplification of specific endoglucanase gene sequence for detection of the bacterial wilt pathogen Ralstonia solanacearum. PloS One, 9(4), e96027.

Margaria, P., Turina, M., \& Palmano, S. (2009). Detection of flavescence doree and bois noir phytoplasmas, Grapevine leafroll associated virus- 1 and -3 and Grapevine virus $A$ from the same crude extract by reverse-transcription real-time Taqman assays. Plant Pathology, 58(5), 838-845.

Mehle, N., Nikolić, P., Rupar, M., Boben, J., Ravnikar, M., \& Dermastia, M. (2013a). Automated DNA extraction for large numbers of plant samples. In M. Dickinson \& J. Hodgetts (Eds.), Phytoplasma methods and protocols (pp. 139-145). London: Humana Press.

Mehle, N., Prezelj, N., Hren, M., Boben, J., Gruden, K., Ravnikar, M., et al. (2013b). A real-time PCR detection system for the bois noir and flavescence doree phytoplasmas and quantification of the target DNA. In M. Dickinson \& J. Hodgetts (Eds.), Phytoplasma methods and protocols (pp. 253-268). London: Humana Press.

Notomi, T., Okayama, H., Masubuchi, H., Yonekawa, T., Watanabe, K., Amino, N., et al. (2000). Loop-mediated isothermal amplification of DNA. Nucleic Acids Research, 28, e63.

Pelletier, C., Salar, P., Gillet, J., Cloquemin, G., Very, P., Foissac, $X$., et al. (2009). Triplex real-time PCR assay for sensitive and simultaneous detection of grapevine phytoplasmas of the $16 \mathrm{SrV}$ and $16 \mathrm{SrXII}-\mathrm{A}$ groups with an endogenous analytical control. Vitis, 48(2), 87-95.

Prezelj, N., Nikolić, P., Gruden, K., Ravnikar, M., \& Dermastia, M. (2013). Spatiotemporal distribution of flavescence dorée phytoplasma in grapevine. Plant Pathology, 62(4), 760-766.

Quaglino, F., Zhao, Y., Casati, P., Bulgari, D., Bianco, P. A., Wei, W., et al. (2013). "Candidatus phytoplasma solani", a novel taxon associated with stolbur- and bois noir-related diseases of plants. International Journal of Systematic and Evolutionary Microbiology, 63(8), 2879-2894.

Tomlinson, J. A., Boonham, N., \& Dickinson, M. (2010a). Development and evaluation of a one-hour DNA extraction and loop-mediated isothermal amplification assay for rapid detection of phytoplasmas. Plant Pathology, 59(3), 465-471.

Tomlinson, J. A., Dickinson, M. J., \& Boonham, N. (2010b). Rapid detection of Phytophthora ramorum and P. kernoviae by two-minute DNA extraction followed by isothermal amplification and amplicon detection by generic lateral flow device. Phytopathology, 100, 143-149. 